\title{
Herramientas estratégicas para la propuesta de modelo de cadena productiva forestal para Arauca, Colombia ${ }^{1}$
}

\author{
Strategic tools to formulate a proposal for a forest productive chain \\ model for Arauca, Colombia
}

\section{Ferramentas estratégicas para o modelo de cadeia produtiva florestal proposta para Arauca, Colômbia}

Andrea C. Padilla-Puerta', Luz A. Montoya-Restrepo ${ }^{2}$ Iván A. Montoya-Restrepo ${ }^{3}$

1 Ing Ambiental, MSc, Universidad Cooperativa de Colombia, Sede Arauca
2 Adm Epresas, MSc,PhD, Facultad de Minas, Universidad Nacional de Colombia
3 Adm Empresas, MSc, PhD Facultad de Minas, Universidad Nacional de Colombia
Email: iamontoyar@unal.edu.co

Recibido: julio 21 de 2015

Aceptado: octubre 23 de 2018

\section{Resumen}

En el presente artículo se realizó un análisis diagnóstico con miras a identificar acciones para favorecer la consolidación de una cadena productiva forestal en Arauca, Colombia, como estrategia de desarrollo. A partir de una investigación de tipo cualitativo, con consulta a expertos y con una metodología de planeación participativa, se desarrolló un análisis de debilidades, fortalezas, oportunidades y amenazas (DOFA). También se identificaron elementos que dieron soporte para un posterior análisis Mactor ${ }^{\circledR}$ (Matriz de alianzas y conflictos, tácticas, objetivos y recomendaciones) para identificar intereses de los actores de la cadena, y finalmente se propuso un modelo de representación de la cadena productiva forestal del departamento, con sus respectivos eslabones y agentes.

Palabras claves: Alianzas estratégicas, forestería, Mactor.

\section{JEL Classification System}

L22 Firm Organization and Market Structure

L60 General

L73 Forest Products

M21Business Economics

\section{Abstract}

In the present article, a diagnostic analysis aimed at identifying actions to favor the consolidation of a forest productive chain in Arauca, Colombia, as a development strategy, was carried out. From a qualitative investigation, with consultation

1 Producto derivado de la tesis de maestría titulada: Propuesta de formulación de la cadena productiva forestal del departamento de Arauca, Disponible en: http://bdigital.unal.edu.co/42017/1/7709576.2014.pdf 
to experts and with a methodology of participative planning, an analysis of weaknesses, strengths, opportunities and threats was developed (SWOT). Elements also were identified, to gave support for a subsequent Mactor ${ }^{\circledR}$ analysis (Matrix of alliances and conflicts, tactics, objectives and recommendations) in order to identify interests of the actors in the chain, and finally was proposed a model of representation of the forest productive chain of the department, with its respective links and agents.

Keywords: Strategic alliances; forestry; Mactor.

\section{Resumo}

No presente artigo, foi realizada uma análise diagnóstica que objetivou identificar ações para favorecer a consolidação de uma cadeia produtiva florestal em Arauca, Colômbia, como estratégia de desenvolvimento. A partir de uma investigação do tipo qualitativa, com consulta a especialistas e com uma metodologia de planejamento participativo, foi desenvolvida uma análise de Forças, Fraquezas, Oportunidades e Ameaças (SWOT). Elementos que deram suporte para uma análise Mactor ${ }^{\circledR}$ subsequente (Matriz de alianças e conflitos, táticas, objetivos e recomendações) para identificar os interesses dos atores da cadeia também foram identificados e, finalmente, um modelo de representação da cadeia de produção florestal da departamento, com seus respectivos links e agentes.

Palavras-chave: Alianças estratégicas; silvicultura; Mactor.

\section{Introducción}

Los modelos de integración empresarial facilitan a las organizaciones mejorar su desempeño, al aprovechar sus ventajas competitivas y comparativas para explotar las capacidades organizacionales de la mejor manera (Montoya y Montoya, 2011). En Colombia el Ministerio de agricultura y diferentes entidades del orden nacional y territorial (LEY 811 DE 2003) apoyados por instituciones internacionales han asistido la consolidación de las cadenas productivas como modelos a seguir en especial para el sector primario (Montoya, 2010, Peña y Rodriguez 2008).

En el caso de la producción forestal, los sistemas boscosos naturales se han convertido en los principales promotores de agronegocios en el mundo (FAO, 2005, 2011, 2012), por su potencial y aprovechamiento. Un modelo de cadena productiva posibilita "los aspectos de producción primaria, procesamiento, transformación y todas las actividades de almacenamiento, distribución y comercialización" (IICA, 2010, p. 1), su prinicipal aporte se centra en la importancia como fuente de materias primas (desde los servicios de agroforestería y silvopastoriles) y servicios ambientales asociados a sistemas ecosistémicos (Rodríguez y Vargas, 2018, Hernández J, et al., 2018), así como la promoción del rendimiento económico de los territorios (Casas, E, 2018).

Sin embargo, el reto es significativo, a pesar de que Colombia tiene tanto potencial, múltiples dificultades afrontan las organizaciones de este importante sector de la economía:

"Colombia es un país de bosques. Desde la neblina que se enreda en los árboles de los Andes hasta los moricha- les de la Orinoquía, pasando por las selvas del Chocó y la Amazonía, el Ideam calcula que 53\% del territorio nacional está cubierto de bosques. Ahí vive buena parte de las 55.000 especies animales y vegetales que tiene Colombia y de ellos dependen cientos de miles de personas" (WWF, 2019).

Con este gran potencial, de 59.9 millones de hectáreas de bosque natural, que ha llevado al país a ser considerado como uno de los de mayor cobertura de Bosque tropical, se encuentra en alto riesgo. De acuerdo con el boletín de alertas tempranas del IDEAM: "El Análisis regional, generado en conjunto por el Ideam, Corpoamazonía, la Corporación para el Desarrollo sostenible del Norte y Oriente Amazónico (CDA) y Cormacarena, identificó cerca de 43.000 ha deforestadas en estos departamentos durante el trimestre" (IDEAM, 2019).

Hacer de este sistema productivo, uno rentable y sostenible se convierte en una posibilidad para el desarrollo de la región (Gobernación de Arauca, 2002,2011, 2012, 2019, DNP, 2011). Es por esto por lo que, en el presente documento, se revisan potencialidades de la cadena productiva en el Departamento de Arauca.

Primero se presentará la metodología seguida para la propuesta, posteriormente los retos que afronta este sistema de integración y se mostrará la alternativa para su consolidación.

\section{Metodologia}

Para el desarrollo de este documento se utilizó la metodología deductiva-analítica para el análisis y la fragmentación del objeto de estudio, posteriormente se utilizó la metodología de síntesis estratégica que posibilita la presentación de la cadena. 
Esta metodología de investigación cualitativa (Hernández, 2010), posibilitó conseguir información secundaria en diferentes tipos de fuentes y también se recurrió a los actores relacionados en el departamento para su identificación.

La metodología de construcción de la cadena siguió los lineamientos metodológicos propuestos por el Grupo de Investigación BioGestión y el Ministerio de Agricultura y Desarrollo Rural (Ministerio de Agricultura 2011,2005,2007, 2008, Castellanos et al., 2011 (Padilla et al., 2015). Se eligieron un total de (7) expertos de la cadena para realizar una investigación exploratoria, personas reconocidas en los municipios a la capital del Departamento y en ésta, así como en la Gobernación de Arauca, que conocen la dinámica del sector y se realización entrevistas semiestructuradas.

Posterior al análisis estratégico realizado con la herramienta de diagnóstico DOFA, la cual arroja cursos de acción por la vía de cruces entre oportunidades, fortalezas, debilidades y amenazas, se realizó un análisis de juego de actores mediante el análisis MACTOR®, el cual indaga sobre sus alianzas y conflictos, a través de la identificación de objetivos ligados a variables claves y retos que son perseguidos por los mencionados actores. Este análisis es relevante porque permite conocer la intención de los actores para la consolidación de alianzas en sistemas, donde participan diferentes agentes. El método parte por identificar los actores más relevantes que influyen sobre las principales variables de la cadena. También deben identificarse los objetivos estratégicos que persiguen los actores articulados a las variables claves o retos de la cadena, los cuales se presentan en la figura No.1 de diagnóstico estratégico y herramienta MACTOR ${ }^{\circledR}$ (Arcade, et al., 2004, Godet, 1993). Los análisis permiten identificar la convergencia y divergencia entre los actores, mediante el análisis del número de objetivos para los cuales los actores $i$ y $j$ tienen posiciones comunes, bien sean favorables o desfavorables (convergencias) (ncij) y además establecer el número de objetivos para los cuales los actores $i$ y $j$ tienen una posición divergente (ndij), y que se introducen en la casilla correspondiente al cruce entre los actores.

\section{Problemática del sector}

El departamento de Arauca es una región en desarroIlo, que cuenta con retos fronterizos. Su clima y calidad de sus suelos proporciona condiciones ambientalmente favorables, relacionadas con la existencia de vastas tierras con vocación de uso del suelo para el desarroIlo de cultivos forestales comerciales (Gobernación de Arauca, 2019, DNP, 2011, Fundaset, 2006).

Se espera que el departamento pueda colaborar con las iniciativas del Ministerio de Medio ambiente, en disminuir la deforestación y el aumento de la proporción productiva del país:

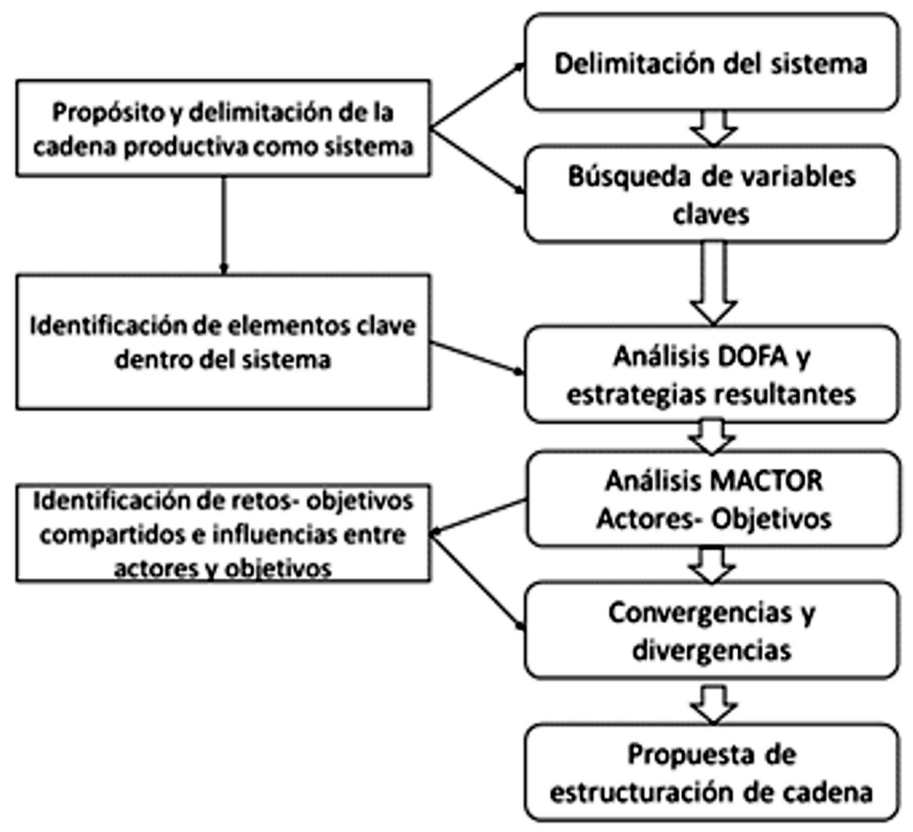

Figura 1. Esquema de la investigación

Fuente: La investigación 
"En 2020 vamos a disminuir la deforestación en un 20\% respecto a los cálculos que muestra el modelo. Es decir, será de 252 mil hectáreas, aproximadamente. Y para 2022 la disminuiremos en un 30\%, aproximadamente. Eso quiere decir que ese año la tala ilegal no sobrepasará las 252 mil hectáreas comparada con la tendencia del modelo que muestra una degradación de 360 mil hectáreas" (EL Espectador, 2019)

El potencial del Departamento de Arauca, para el desarrollo de la cadena productiva forestal (Corpoica, 2016, DNP, 2011, Corporinoquia, 2008, 2013, Zapata J y Rueda A, 2015) y el Diagnóstico, del Plan Estratégico de Productividad y Competitividad del Departamento de Arauca (2005), formularon posibilidades para el departamento de más de 1.8 millones de hectáreas, con miras al establecimiento de cultivos forestales comerciales, representando un $76 \%$ del territorio total del mismo.

Según el censo del DANE, Arauca contaba a 2014 con las siguientes hectáreas de utilización agropecuaria:
Así también la tabla No. 2 muestra la caracterización de los cultivos a 2011.

\section{Cadena productiva Forestal}

La cadena forestal, madera y muebles, comprende la producción de madera (en bosques naturales o plantaciones forestales), las actividades de explotación de la madera (tala de árboles y extracción de la madera en rollo), aserrado y la fabricación de muebles y accesorios (Navarro, 2011, DNP, 2004); los retos que enfrenta el sector se relacionan con el acceso a las tierras, el conflicto, la infraestructura y barreras propias del sector que pueden observarse en la Figura 3.

La estrategia de la cadena productiva forestal Nacional tiene como meta de reforestación comercial alrededor de 170.000 has, para el año 2025, y un programa de reforestación comercial en la región de 500.000 has aproximadamente para el año 2025, (FEDEMADERAS, 2011). A pesar de este propósito, puede apreciarse

Tabla 1. Áreas totales

\begin{tabular}{|c|c|c|c|c|}
\hline $\begin{array}{c}\text { Área total } \\
\text { (ha) }\end{array}$ & $\begin{array}{c}\text { Área (ha) } \\
\text { en bosques } \\
\text { naturales }\end{array}$ & $\begin{array}{c}\text { Área (ha) } \\
\text { con uso } \\
\text { agropecuario }\end{array}$ & $\begin{array}{c}\text { Área (ha) } \\
\text { con uso no } \\
\text { agropecuario }\end{array}$ & $\begin{array}{c}\text { Área (ha) con otros } \\
\text { usos y cobertura } \\
\text { de la tierra }\end{array}$ \\
\hline 2.346 .578 & 568.276 & 1.708 .774 & 32.289 & 37.239 \\
\hline
\end{tabular}

Fuente: Dane, 2014

\section{Departamento de Arauca}
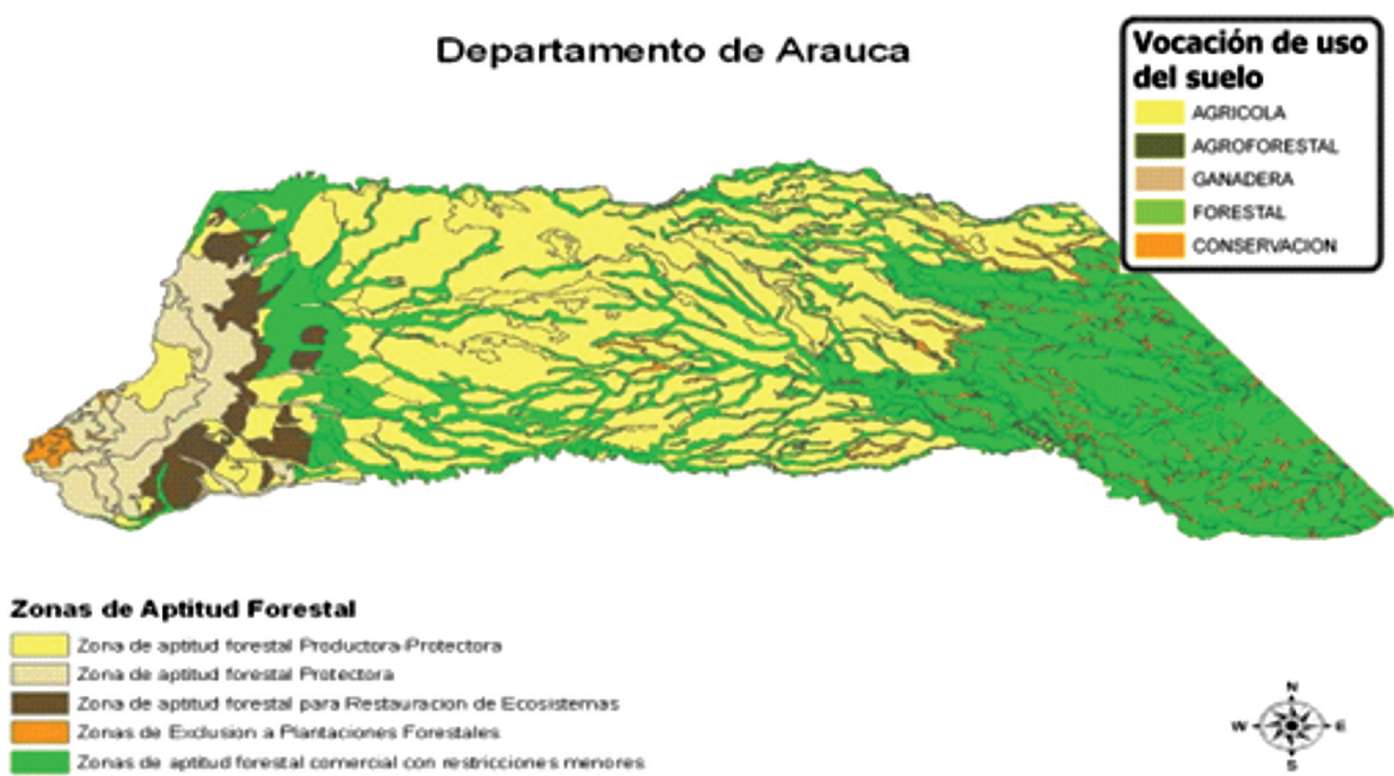

Fuente: CONIF-, 2001. Cálculos IICA-OT

Figura 2. Zonificación forestal departamento de Arauca a 2001 
Tabla 2. Caracterización de los cultivos del departamento

\begin{tabular}{|c|c|c|}
\hline Bosque & Caracterización & Especies \\
\hline $\begin{array}{l}\text { Bosque } \\
\text { natural } \\
\text { (primario) }\end{array}$ & $\begin{array}{l}\text { Corresponde a la cobertura de vegetación arbórea } \\
\text { nativa no } \\
\text { plantada de más de } 8 \text { metros de altura, los cuales } \\
\text { forman por lo menos un estrato de copas } \\
\text { (dosel) más o menos continuo donde los árboles } \\
\text { tienen una cubierta aparente (proyección } \\
\text { vertical al suelo de la corona) superior al } 90 \% \text {. }\end{array}$ & $\begin{array}{l}\text { Por la gran influencia antrópica que se da en el municipio, el bosque } \\
\text { se presenta de manera dispersa como relictos. Las especies dominan- } \\
\text { tes son: Flor amarillo (Mollis sp), Ceiba tolúa (Pachira quinatum), Par- } \\
\text { dillo (Cordia alliodora), Mosco (Terminalia sp.), Yarumo o Guarumo } \\
\text { (Cecropia sp.), Laurel (Ocotea sp.), Bucaro (Eritrina fusca), Guadua } \\
\text { (Guadua angustifolia), Palma real (Attalea regia), Samán (Pithecello- } \\
\text { bium saman), Trompillo (Guarea guidonia), Cedro (Cedrela odorata), } \\
\text { Totumo (Crescentia cujete) y Hobo (Spondias mombin). }\end{array}$ \\
\hline $\begin{array}{l}\text { Bosque } \\
\text { secundario: }\end{array}$ & $\begin{array}{l}\text { Corresponde a elementos típicamente arbóreos de } \\
\text { más de } 8 \text { metros de altura, asociado con matorrales } \\
\text { y arbustos; con un grado alto de intervención (frag- } \\
\text { mentados) como resultado de la destrucción parcial } \\
\text { o total del bosque natural, especialmente por la } \\
\text { ampliación de la frontera agrícola, ganadera y los } \\
\text { desarrollos urbanos y petroleros. }\end{array}$ & $\begin{array}{l}\text { Las especies dominantes en esta unidad incluidas algunas introduci- } \\
\text { das, son: Palma real (Attalea regia), Dividivi (Caesalpiniaceae coriaria), } \\
\text { Marañón (Anacardium occidentale), Naranja dulce (Citrus sinensis), } \\
\text { Naranja amarga (Citrus aurantium) y Mandarina (Citrus nobilis), Me- } \\
\text { lina (Gemelita arbórea), Teca (Tectona grandis), Flor amarillo (Mollis } \\
\text { sp), Jabillo (Hura crepitans L.), Guarataro (Vitex orinocensis), Escobilla, } \\
\text { Ziracuta (Scoparia dulcis), entre otras especies. }\end{array}$ \\
\hline $\begin{array}{l}\text { Bosque de } \\
\text { Galería }\end{array}$ & $\begin{array}{l}\text { Esta cobertura hace referencia a zonas de bosque } \\
\text { localizadas a lado y lado de las corrientes de agua } \\
\text { de la cuenca, especialmente en las planicies aluvia- } \\
\text { les. Son los más representativos en la región por su } \\
\text { amplia distribución y presentan diferente grado de } \\
\text { intervención. Se encuentran a lo largo de caños y } \\
\text { ríos con especies vegetales de } 5 \text { a } 8 \text { m de altura } \\
\text { en promedio. Esta formación ha sido intervenida } \\
\text { en largos trechos para dar paso a la agricultura y } \\
\text { la ganadería. } \\
\text { Los bosques de galería y relictos de bosque secun- } \\
\text { dario son ecosistemas estratégicos que cumplen la } \\
\text { función de mantenimiento del equilibrio ecológico } \\
\text { y de la biodiversidad ya que, contribuyen a la regu- } \\
\text { lación climática e hídrica, conservación de suelos } \\
\text { y depuración de la atmósfera. Así mismo interco- } \\
\text { nectan y dispersan el germoplasma de las selvas y } \\
\text { sabanas }\end{array}$ & $\begin{array}{l}\text { En general, las especies vegetales de mayor dominancia en este tipo } \\
\text { de cobertura son Guarataro (Vitex osinocense), Laurel (Ocotea sp.), } \\
\text { Yarumo (Cecropia teleincana), Guamo de agua (Pithecollobium sp.), } \\
\text { Flor amarillo (Mollis sp.), Guayabo de agua (Eugenia sp.), Caujaro } \\
\text { (Cordia tetrandra), Saladillo (Vochysia punctata) y Lechero (Perebea } \\
\text { sp.) entre otras. Los muestreos de vegetación en los bosques de ga- } \\
\text { lería, dan cuenta de especies tales como Aceite (Copaifera pubiflora), } \\
\text { Anoncillo (Dugüetia riparia), Bototo (Cochlospermum sp.), Canilla de } \\
\text { venado (Mabea nítida), Guarataro (Vitex orinocense), Guayabo rebal- } \\
\text { sero (Psidium maribense), Hobo (Spondias mombin), Casave (Tapiria } \\
\text { guianensis), Reventillo (Mabea parvifolia), Chipion (Maclura tinctoria) y } \\
\text { Saladillo blanco (Vocysia lehmanii), entre otras. }\end{array}$ \\
\hline $\begin{array}{l}\text { Comer- } \\
\text { ciales }\end{array}$ & & $\begin{array}{l}\text { Las especies arbóreas más frecuentes son: Cedro (Cedrela sp), Cara- } \\
\text { ño (Dacryodes sp), Laurel (Ocotea sp), Guarataro (Vitex orinocensis) } \\
\text { Anime (Protium sp), Gualanday (Jaracanda spp.), Yarumo (Cecropia } \\
\text { sp), Caimo (Pouteria sp), Guadua (Bambusa spp.), Guamos (Inga } \\
\text { spp.), Saladillo (Vochysia punctata), Palma real (Attalea regia), Palma } \\
\text { de cuesco (Attalea nucifera) y Palma mil pesos (Jessenia polycarpa), } \\
\text { asociadas con especies arbustivas como: Pata de tórtola (Croton hir- } \\
\text { tus), Cadillo (Desmodium spp.), Brusca (Cassia spp.), Yayito (Xylopia } \\
\text { sp.) y Mastranto criollo (Salvia palaefolia). En algunos sectores es posi- } \\
\text { ble encontrar cultivos de Cacao (Theobroma cacao) y Platano (Musa } \\
\text { paradisiaca); así como potreros utilizados para ganadería extensiva, } \\
\text { cubiertos con pastos de Brachiaria (Brachiaria decumbens) y (Brachia- } \\
\text { ria umidicola), Paja llanera (Trachypogon vestitus) y Rabo de zorro } \\
\text { (Andropogon bicornis). }\end{array}$ \\
\hline $\begin{array}{l}\text { Arbustos } \\
\text { y mato- } \\
\text { rrales: }\end{array}$ & $\begin{array}{l}\text { Corresponde a la vegetación de porte bajo, por lo } \\
\text { general producto de actividades antrópicas, cons- } \\
\text { tituyendo un estado sucesional temprano, carac- } \\
\text { terizado por cubiertas vegetales donde sus copas } \\
\text { pueden estar juntas o esparcidas entre sí. Este estra- } \\
\text { to posee una altura comprendida entre } 1,5 \text { y } 8 \mathrm{~m} \text {. }\end{array}$ & $\begin{array}{l}\text { Palma real (Attalea regia), Dividivi (Caesalpiniaceae coriaria), Mara- } \\
\text { ñón (Anacardium occidentale), Naranja dulce (Citrus sinensis), Na- } \\
\text { ranja amarga (Citrus aurantium) y Mandarina (Citrus nobilis), Melina } \\
\text { (Gemelita arbórea), Teca (Tectona grandis), Flor amarillo (Mollis sp), } \\
\text { Jabillo (Hura crepitans L.), Guarataro (Vitex orinocensis), Escobilla, Zi- } \\
\text { racuta (Scoparia dulcis), entre otras especies; asociadas con especies } \\
\text { arbustivas como Pata de tórtola (Croton hirtus), Cadillo (Desmodium } \\
\text { spp.), Brusca (Cassia spp.) Cresta de gallo (Celosia cristata L.), Yayito } \\
\text { (Xylopia sp.) y Mastranto (Criollo) (Salvia palaefolia). }\end{array}$ \\
\hline
\end{tabular}

Fuente: Alcaldía de Arauca, 2011 


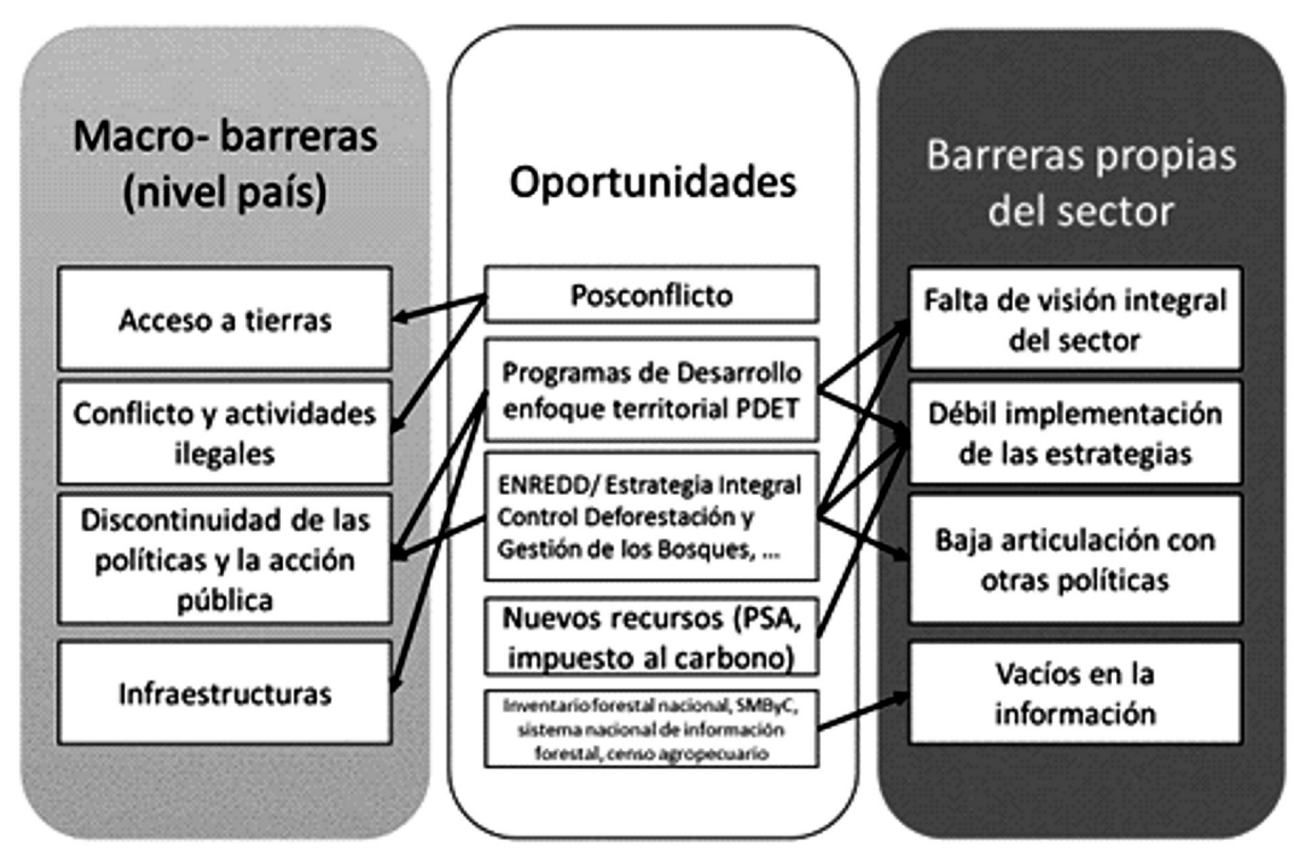

Figura 3. Principales Barreras y oportunidades para el sector forestal Fuente: Merle, 2018 p. 16

que la cadena como tal no se encuentra suficientemente consolidada y que se requiere robustecerla para cumplir con los objetivos propuestos.

\section{Resultados y discusión}

Para la propuesta de cadena productiva se realizaron diferentes talleres en 2014, con productores regionales acompañados de órganos institucionales como la gobernación, la alcaldía y Corporinoquia en el cual se obtuvieron diagnósticos estratégicos del sector, los cuales fueron condensados en (Padilla, 2014). Por su parte, (Botero E, y Padilla A, 2015) encontraron como principales características del sector las que se observan en la tabla 3.

El esfuerzo se concentró en entender la Matriz DOFA (Espinosa, 2013) para el desarrollo de estrategias (Tabla 4).

Con los expertos participantes en los talleres se realizó un proceso de priorización dando como resultado la siguiente matriz de estrategias a desarrollar. El resultado de esta calificación fue el siguiente (Tabla 5).

El análisis estratégico mostró las siguientes particularidades:

- Falta de personal calificado que posibilite desarrollar y acumular capacidades al interior de cada eslabón,
- Profundizar en el conocimiento y oportunidades para el sector.

- Favorecer la promoción de la inversión en el sector, con base en su propicia vocación forestal

- Generar producción de bienes y servicios ambientales del bosque ya plantado,

- Reducir sistemáticamente presiones sobre áreas boscosas naturales.

Como principales estrategias resultantes de la DOFA para la cadena se encuentran:

1. El Departamento debe enfocar sus esfuerzos en la consecución de recursos provenientes de fuentes de financiación nacional e internacional, que permita el aprovechamiento de la vocación forestal del territorio y el desarrollo de acciones concretas en torno a la cadena productiva forestal, priorizada para el Departamento.

2. Aprovechar la tendencia mundial hacia la protección ambiental para enfocar la búsqueda de mercados reales y potenciales para la comercialización, no sólo de productos cosechados, sino también de productos vivos (productos en pie) y de servicios ambientales, generados en el territorio departamental, a través de las nuevas áreas plantadas. 
Tabla 3. Características del sector

\begin{tabular}{|l|l|}
\hline \multicolumn{1}{|c|}{ Aspectos de análisis } & \multicolumn{1}{|c|}{ Características encontradas en el departamento de Arauca } \\
\hline $\begin{array}{l}\text { Connotación social de } \\
\text { la actividad económica }\end{array}$ & $\begin{array}{l}\text { Aporta a la economía familiar de las comunidades rurales } \\
\text { Integración familiar en torno a la actividad } \\
\text { Generación de empleo rural } \\
\text { Soporte institucional para atención a la población vulnerable. }\end{array}$ \\
\hline \multirow{5}{*}{$\begin{array}{l}\text { Mejora de procesos } \\
\text { productivos }\end{array}$} & $\begin{array}{l}\text { Procesos incipientes y pocos tecnificados } \\
\text { Ausencio de investigación y desarrollo en el sector } \\
\text { Baja capacidad de transformación y valor agregado. }\end{array}$ \\
\hline \multirow{5}{*}{$\begin{array}{l}\text { Características de la } \\
\text { cadena productiva }\end{array}$} & $\begin{array}{l}\text { Débil capacidad de negociación e interrelación entre eslabones. } \\
\text { Ausencia de plantaciones forestales comerciales } \\
\text { en el territorio (eslabón primario). } \\
\text { Debilidad para atender la demanda local de productos } \\
\text { y servicios forestales del territorio. } \\
\text { Debilidad en el desarrollo de procesos de } \\
\text { innovación y mejoramiento en el sector. }\end{array}$ \\
\hline \multirow{5}{*}{$\begin{array}{l}\text { Percepción de la } \\
\text { acción estatal }\end{array}$} & $\begin{array}{l}\text { Debilidad en el desarrollo de acciones enfocadas en el fortalecimiento del sector } \\
\text { Existencia de iniciativas institucionales que favorecerín la implementación de la } \\
\text { cadena productiva, aún no desarrolladas. } \\
\text { Falencias en la promoción empresarial de la actividad forestal, } \\
\text { por parte de la institucional del departamento de Arauca. }\end{array}$ \\
\hline
\end{tabular}

Fuente: Botero E. \& Padilla A. (2015). P. 46

3. Es necesario desarrollar procesos de investigación aplicada (Corpoica (2016) que permitan generar productos y servicios ambientales, acordes con los requerimientos de los mercados identificados, favoreciendo la producción y la transformación sostenible, generando al mismo tiempo confianza en potenciales inversionistas, tanto públicos como privados.

4. Promover la generación de procesos de asociatividad y de creación de empresa, apoyados en fuentes de financiación nacional e internacional.

5. Generar procesos de cualificación de personal, en el nivel técnico, tecnológico y profesional, con enfoque en el sector forestal, en instituciones educativas con asiento en el departamento de Arauca.

6. Priorizar áreas con vocación forestal para el inicio de actividades relacionadas con el eslabón de producción y establecer un orden escalonado de aprovechamiento de la vocación forestal del suelo, programando cronológicamente, de esta manera, las intervenciones, en un entorno de post-acuerdo.

7. Desarrollar mecanismos económicos y técnicos para reducir los altos costos de transporte de pro- ductos forestales desde zonas de producción hasta zonas de transformación y/o comercialización, dentro de la cadena.

8. La mezcla de elementos internos y externos que influyen negativamente en el desarrollo del sector, determina la necesidad de fortalecer la articulación entre entes nacionales y regionales visibilizando la necesidad de la conformación de la cadena (Padilla,2014).

Una vez identificadas dificultades y potencialidades del sector forestal, se adelantó en (Padilla, 2014) un ejercicio MACTOR ${ }^{\circledR}$, en donde se especifican los objetivos perseguidos por los actores con relación a las variables claves.

De acuerdo con este diagnóstico se presenta la identificación de variables claves a manera de retos, los cuales articulan objetivos compartidos por los actores de la cadena, en la tabla 6.

Con base en los objetivos asociados a los retos identificados, se realizó la matriz de posiciones de actores por objetivos MACTOR ® (Arcade, et al., 2004, Godet, 1993). Los actores calificaron de la siguiente manera: $(+1)=$ el actor se encuentra a favor del objetivo eva- 
Tabla 4. DOFA generada a través de entrevistas con los actores identificados para la cadena productiva forestal del departamento de Arauca.

\begin{tabular}{|l|}
\hline \multicolumn{1}{|c|}{ Fortalezas } \\
\hline Vocación forestal del Departamento. \\
Existencia de grandes extensiones de tierra subutilizadas, aptas \\
para proyectos forestales. \\
Priorización cadena forestal como alternativa de desarrollo eco- \\
nómico en el Departamento. \\
Existe interés por parte del gobierno nacional y local en impulsar \\
el desarrollo de la cadena productiva forestal en el departamento \\
de Arauca, mediante el establecimiento de plantaciones comer- \\
ciales. \\
Existencia de mecanismos institucionales para el desarrollo del \\
sector forestal que pueden ser trabajados. \\
Cooperación internacional para contribuir en la conservación de \\
los bosques naturales y su biodiversidad, favoreciendo el desarro- \\
llo de plantaciones forestales comerciales. \\
Gran diversidad de especies con alto valor comercial y diversidad \\
de usos. \\
Disponibilidad de mano de obra no calificada.
\end{tabular}

Oportunidades

Posición geográfica estratégica para incursionar en los principales mercados de Colombia y Venezuela con productos forestales, donde se demanda madera procesada y muebles.

Identificación de mercados o segmentos y ampliación del portafolio de productos y servicios para satisfacer nuevas necesidades de los clientes, incluyendo los bonos de emisiones y la venta de madera en pie.

Mercado demandante de maderas tropicales y maderas finas a nivel nacional y mundial.

Identificación de potenciales fuentes de financiación y cooperación pública y privada, para el desarrollo de proyectos productivos.

Inversión privada manifestada a través de la creación de empresa, con planes definidos de inversión y recuperación de esta en el corto y mediano plazo.

La visión de la Orinoquia como una zona con alto potencial agroindustrial.

Existe un fuerte llamado a nivel mundial por el desarrollo de procesos productivos sostenibles, los cuales favorecen la recuperación de los esquemas boscosos considerados de gran importancia en la regulación de ciclos biogeoquímicos y de soporte de la biodiversidad, los cuales tienen mayor cabida en el mercado.

Precios de la madera en mercados nacionales e internacionales.

Turnos de corte más rápidos de especies forestales competitivas, las cuales podrían ser aprovechadas en cultivos forestales del Departamento.

\begin{tabular}{|c|}
\hline Debilidades \\
\hline Ausencia de procesos de investigaron aplicada al sector forestal.
\end{tabular}

Ausencia de procesos de investigación aplicada al sector forestal. Desconocimiento de la flora nativa del departamento de Arauca. Existe una marcada falta de educación forestal dirigida a productores y, en general, a la comunidad del Departamento.

Resistencia al cambio por parte de los dueños de tierra, reflejada en la preferencia que tienen éstos por el establecimiento de cultivos tradicionales y por el desinterés de los agricultores en conocer los beneficios económicos y ecológicos de la producción forestal. Falta de infraestructura y maquinaria para el desarrollo forestal (lugares de procesamiento de maderas).

Relación costo/beneficio alto para el aprovechamiento de establecimientos forestales comerciales.

Ausencia de inversiones en proyectos forestales comerciales en la zona.

Infraestructura vial deficiente.

Alto costo de insumos y mano de obra en las zonas rurales.

Ausencia de apoyos gubernamentales para incentivar el desarrollo de la cadena productiva forestal.

El CIF está aprobado para ciertas especies que no son económicamente viables en el departamento.

Existen dificultades en el acceso a incentivos forestales y otros apoyos gubernamentales relacionados con el sector.

Hay debilidad en la visión departamental, debido a que no se ha logrado definir el proceso a través del cual se lograría el desarrollo del sector forestal y, en consecuencia, de su cadena productiva.

Hay una escasa participación de las plantaciones forestales como alternativa de producción de bienes y servicios ambientales.

Hay explotación insostenible y desordenada del bosque natural, aún con permisos generados por la autoridad ambiental.Existe una fuerte tendencia cultural hacia la extracción sin recuperación del bosque natural, lo que ha ocasionado la reducción de las áreas boscosas del Departamento.

\section{Amenazas}

Sostenimiento y agudización del conflicto armado, manifestado en la realización de los denominados "paros armados" y el cierre total de vías intermunicipales y nacionales, además de la consecuente sensación de inseguridad.

La frontera como un factor de generación de inestabilidad ocasionada por las relaciones con el Estado colombiano, el contrabando de maderas de interés comercial a través del río y los bajos precios en los insumos agrícolas en el vecino país.

Deficiente grado de desarrollo tecnológico para la producción de bienes elaborados de madera.

Largo ciclo de producción, debido a los ciclos naturales de producción de un árbol.

Incorporación de especies no aptas para el departamento (pino y eucalipto).

Gran número de intermediarios en el proceso de comercialización, desde el corte hasta el consumidor, favoreciendo la extracción de madera del bosque natural debido a los bajos márgenes de ganancias. Incendios de coberturas vegetales.

Favorecimiento de grandes capitales frente a los pequeños productores de la zona.

Incremento en las ventas de productos sustitutos de la madera.

Cambio en las necesidades y preferencias de los consumidores de productos y servicios.

Entrada de nuevos competidores con costes más bajos.

Incremento de barreras y requisitos reglamentarios que generan mayores costos en la inversión para el desarrollo de proyectos.

La extensión de la agricultura y la ganadería a suelos con vocación forestal.

Altos costos de transporte de los productos forestales para ser llevados a los mercados local y nacional.

Riesgo en la inversión de capitales privados. 


\begin{tabular}{|c|c|}
\hline Debilidades & Amenzas \\
\hline $\begin{array}{l}\text { Baja disponibilidad en el territorio, de profesionales y técnicos del } \\
\text { área forestal. } \\
\text { Escasos planes de reforestación a nivel departamental y de pro- } \\
\text { moción de plantaciones comerciales. } \\
\text { Existen problemas asociados a la gestión empresarial del sector, } \\
\text { manifestada no sólo en la ausencia de formalización; sino también } \\
\text { en el escaso desarrollo de procesos de asociatividad. } \\
\text { Ausencia de iniciativas que generen estrategias que verdadera- } \\
\text { mente promuevan el desarrollo de la cadena productiva forestal. } \\
\text { Debilidad en las instituciones del Estado (entidades territoriales), } \\
\text { manifestadas en el bajo perfil institucional mantenido hasta épo- } \\
\text { cas recientes, que no han permitido que personas interesadas en } \\
\text { el desarrollo del sector forestal conozcan sobre los incentivos, } \\
\text { programas de crédito y potencialidades del cultivo forestal. } \\
\text { Falta de seguimiento de las iniciativas públicas y privadas, realiza- } \\
\text { das en años anteriores. } \\
\text { Ausencia de personal especializado en el sector forestal en las } \\
\text { instituciones del Estado (entidades territoriales). } \\
\text { Requisitos para acceder a créditos y apoyos gubernamentales dif́- } \\
\text { ciles de cumplir por pequeños y medianos productores. }\end{array}$ & $\begin{array}{l}\text { Falta de industria local para evitar la salida de maderas ordinarias del } \\
\text { Departamento. } \\
\text { Crecimiento lento del mercado local. }\end{array}$ \\
\hline
\end{tabular}

Fuente: Padilla, 2014

luado, $(-1)=$ el actor se opone al objetivo evaluado y $(0)=$ el actor es indiferente ante el objetivo, (Tabla 7):

Este análisis permitió visualizar lo siguiente:

- Tres de los nueve actores, están a favor de consolidar la coordinación administrativa de la cadena productiva (Gobernación, Alcaldía y profesionales interesados), lo que proyecta un interés sobre una mayor responsabilidad del Estado en el desarrollo de este objetivo.

- Ocho de los nueve actores, se encuentran a favor de planear y ejecutar acciones enmarcadas en el desarrollo de la cadena productiva.

- Seis de los nueve actores, coincidieron en favorecer la creación de encadenamientos efectivos entre eslabones y sinergias, lograr una mayor calificación técnica y profesional dentro de la cadena, el acceso a recursos económicos y modelos administrativos, así como a la generación de materias primas de calidad, el posicionamiento competitivo de productos y servicios en el mercado local y nacional, y la identificación de mercados nuevos o de diversificación.

- Los nueve actores favorecen el desarrollo de procesos de investigación aplicada a la cadena productiva.

- Ninguno de los actores se mostró en contra del desarrollo de los objetivos asociados (Padilla,2014).
A partir de estas conclusiones, sobrevino la jerarquización de los objetivos, con miras a identificar las tácticas que pueden ser desarrolladas, mediante la matriz de convergencias y divergencias MACTOR ${ }^{\circledR}$ (Arcade, et al., 2004, Godet, 1993). Las convergencias más importantes están entre la gobernación con las alcaldías, y con los actores de producción, transformación y comercialización, así como entre los actores de los mismos eslabones (Figura 4). Ello indica la existencia de un ambiente favorable para el promover los objetivos compartidos mencionados.

Con el fin de complementar el análisis de los actores, se estableció en (Padilla, 2014) las relaciones de fuerza y la posterior formulación de recomendaciones estratégicas, para lo cual se estableció la influencia potencial de un actor sobre otro, en una escala de cero (0) a tres (3), donde: $0=$ influencia potencial nula, $1=$ influencia potencial débil, 2 = influencia potencial media, $3=$ influencia potencial fuerte. Según Godet (2000), "el objeto de esta etapa consiste justamente en integrar la relación de fuerza de cada actor con la intensidad de su posicionamiento en relación a los objetivos" (pág. 66).

En particular se encontró que la Gobernación es el actor más influyente, al ser considerado como un líder de las acciones que puedan desarrollarse alrededor de la cadena productiva y porque es el actor que podría alcanzar los objetivos con mayor facilidad. 
Tabla 5. DOFA producto de la calificación generada por los expertos de la cadena productiva

\begin{tabular}{|c|c|c|c|}
\hline \multicolumn{2}{|r|}{ Debilidades } & \multicolumn{2}{|r|}{ Oportunidades } \\
\hline (D1) & Ausencia de procesos de investigación aplicada & $(\mathrm{O} 1)$ & Identificación de mercados \\
\hline$(\mathrm{D} 2)$ & Desconocimiento del sector & $(\mathrm{O} 2)$ & Identificación de fuentes de financiación \\
\hline (D3) & Baja inversión de recursos públicos en el sector & $(\mathrm{O} 3)$ & $\begin{array}{l}\text { Nuevo enfoque cultural hacia } \\
\text { la protección ambiental }\end{array}$ \\
\hline (D4) & Debilidad en la gestión empresarial del sector & & \\
\hline (D5) & Baja disponibilidad de mano de obra calificada & & \\
\hline & Fortalezas & \multicolumn{2}{|r|}{ Amenazas } \\
\hline$(\mathrm{F} 1)$ & Vocación forestal del Departamento & (A1) & Conflicto armado \\
\hline$(\mathrm{F} 2)$ & Priorización de la cadena productiva forestal & (A2) & Ampliación de la frontera agrícola \\
\hline$(\mathrm{F} 3)$ & $\begin{array}{l}\text { Existencia de mecanismos e instrumentos } \\
\text { de apoyo gubernamental }\end{array}$ & (A3) & Altos costos de transporte \\
\hline
\end{tabular}

Fuente: Padilla, 2014

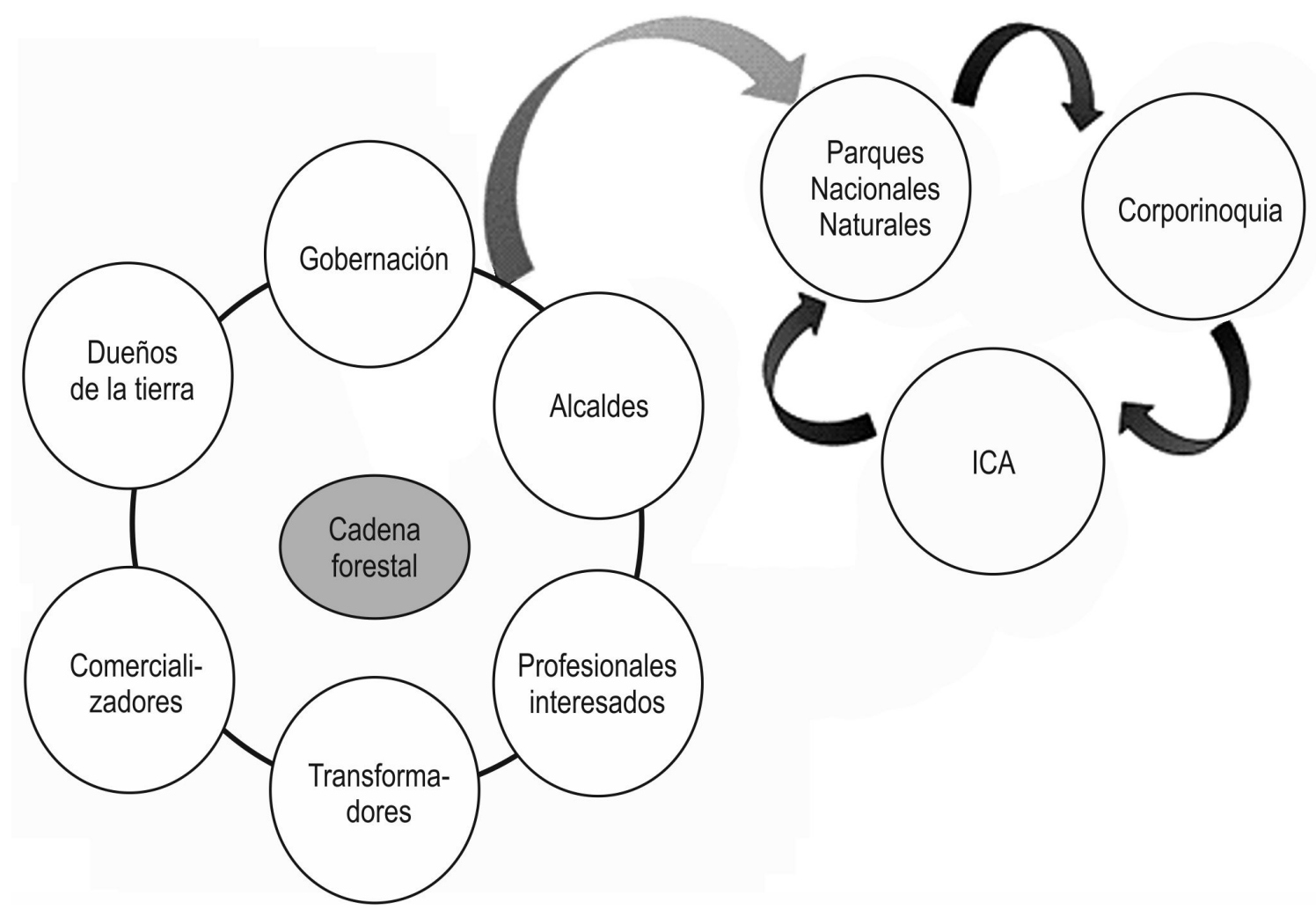

Figura 4. Convergencias de actores de la cadena productiva forestal del departamento de Arauca

Fuente: Padilla, 2014 
Los transformadores, las alcaldías y los comercializadores, a continuación, y finalmente los dueños de tierra y los profesionales interesados (10), se consideraron con influencias potenciales relevantes sobre los demás actores.

Finalmente, se encontró que el actor con menor influencia es Parques Nacionales Naturales, probablemente porque su área de influencia en el departamento corresponde a la zona de piedemonte, en las inmediaciones de Tame y Fortul (municipios del Departamento).

En cuanto a dependencias, la Gobernación y las alcaldías son los actores que tienen mayores dependencias de los demás actores, de manera que se ven afectados por las presiones de los otros actores. También son dependientes, de manera decreciente, los dueños de tierra, los transformadores y comercializadores, si se tienen en cuenta los medios de acción identificados previamente (Padilla, 2014).

En general, se distinguió un ambiente positivo de acción y, en ese sentido, se destaca un ambiente propicio para relaciones directas, sin necesidad de la inclusión de intermediarios. En consecuencia, se pueden consolidar alianzas entre Gobernación y alcaldías, con el propósito de fortalecer la cadena productiva forestal. Consolidaciones potenciales se esperarían con dueños de las tierras (productores), con los transformadores y los comercializadores.

De estos análisis se deriva la representación de la cadena productiva. En la figura 5, se representan eslabones, formas de integración y flujos que podrían propiciar el desarrollo de la cadena productiva forestal en el departamento de Arauca (Padilla, 2014).

Finalmente, se presentaron tanto la caracterización por eslabones (Tabla 8) y sus relaciones (Tabla 9).

\section{Conclusiones}

El presente documento aplicó un modelo de propuesta de cadenas productivas y de elementos de planificación estratégica por medio de herramientas para la decisión estratégica tales como el DOFA y la prospectiva para vislumbrar la cadena productiva forestal del departamento de Arauca. Estas herramientas facilitaron una mayor integración de las prioridades reconocidas para la cadena.

La consolidación de una cadena productiva forestal para el departamento de Arauca, puede dinamizarse a través de un mayor liderazgo de las instituciones públicas territoriales (Gobernación y Alcaldías), lo cual se explica por su capacidad de gestión y por su posibilidad de convocatoria a los demás actores.

Tabla 6. Identificación de variables clave

\begin{tabular}{|c|c|}
\hline Variables claves & Objetivos asociados \\
\hline $\begin{array}{l}\text { 1. Organización de la cadena produc- } \\
\text { tiva forestal en el departamento de } \\
\text { Arauca }\end{array}$ & $\begin{array}{l}\text { O1 - Consolidar la coordinación administrativa de la cadena } \\
\text { productiva forestal en el departamento de Arauca } \\
\text { O2 - Planear y ejecutar acciones enmarcadas en el desarrollo de } \\
\text { la cadena productiva forestal del Departamento de Arauca } \\
\text { O3 - Crear encadenamientos efectivos y sinergias } \\
\text { entre eslabones de la cadena productiva } \\
\text { O4 - Cualificar a los actores vinculados al desarrollo de } \\
\text { la cadena productiva forestal del Departamento } \\
\text { O5 - Acceder a recursos económicos y administrativos que permitan } \\
\text { el desarrollo de acciones en torno a la cadena productiva } \\
\text { O6 - Evaluar la evolución de la ejecución de las acciones de la cadena } \\
\text { productiva forestal del Departamento, en cada período administrativo. }\end{array}$ \\
\hline 2. Investigación aplicada & $\begin{array}{l}\text { O7 - Desarrollar procesos de investigación aplicada a la } \\
\text { cadena productiva forestal del departamento de Arauca }\end{array}$ \\
\hline 3. Oferta de materias primas de calidad & O8 - Generar materias primas de calidad \\
\hline 4. Productos y servicios innovadores & $\begin{array}{l}\text { O9 - Posicionar productos y servicios en el mercado local y nacional } \\
\text { O10 - Identificar nuevos mercados }\end{array}$ \\
\hline
\end{tabular}

Fuente: Padilla, 2014. 
Tabla 7. Matriz de posiciones de actores por objetivos asociados a los retos identificados para la cadena productiva forestal del departamento de Arauca.

\begin{tabular}{|l|c|c|c|c|c|c|c|c|c|c|}
\hline \multicolumn{1}{|c|}{ Actores } & Obj1 & Obj2 & Obj3 & Obj4 & Obj5 & Obj6 & Obj7 & Obj8 & Obj9 & Obj10 \\
\hline Gobernación & +1 & +1 & +1 & +1 & +1 & +1 & +1 & +1 & +1 & +1 \\
\hline Alcaldías & +1 & +1 & +1 & +1 & +1 & +1 & +1 & +1 & +1 & +1 \\
\hline ICA & 0 & 0 & 0 & 0 & 0 & 0 & +1 & 0 & 0 & 0 \\
\hline $\begin{array}{l}\text { Corporinoquia } \\
\text { (Seccional Arauca) }\end{array}$ & 0 & +1 & 0 & 0 & 0 & +1 & +1 & 0 & 0 & 0 \\
\hline $\begin{array}{l}\text { Parques Nacionales } \\
\text { Naturales }\end{array}$ & 0 & +1 & 0 & 0 & 0 & +1 & +1 & 0 & 0 & 0 \\
\hline $\begin{array}{l}\text { Dueños de tierra } \\
\text { (productores) }\end{array}$ & 0 & +1 & +1 & +1 & +1 & +1 & +1 & +1 & +1 & +1 \\
\hline Transformadores & 0 & +1 & +1 & +1 & +1 & +1 & +1 & +1 & +1 & +1 \\
\hline Comercializadores & 0 & +1 & +1 & +1 & +1 & +1 & +1 & +1 & +1 & +1 \\
\hline Profesionales interesados & +1 & +1 & +1 & +1 & +1 & +1 & +1 & +1 & +1 & +1 \\
\hline Resultados a favor (+) & 3 & 8 & 6 & 6 & 6 & 8 & 9 & 6 & 6 & 6 \\
\hline Resultados en contra (-) & 0 & 0 & 0 & 0 & 0 & 0 & 0 & 0 & 0 & 0 \\
\hline
\end{tabular}

Fuente: Padilla, 2014.

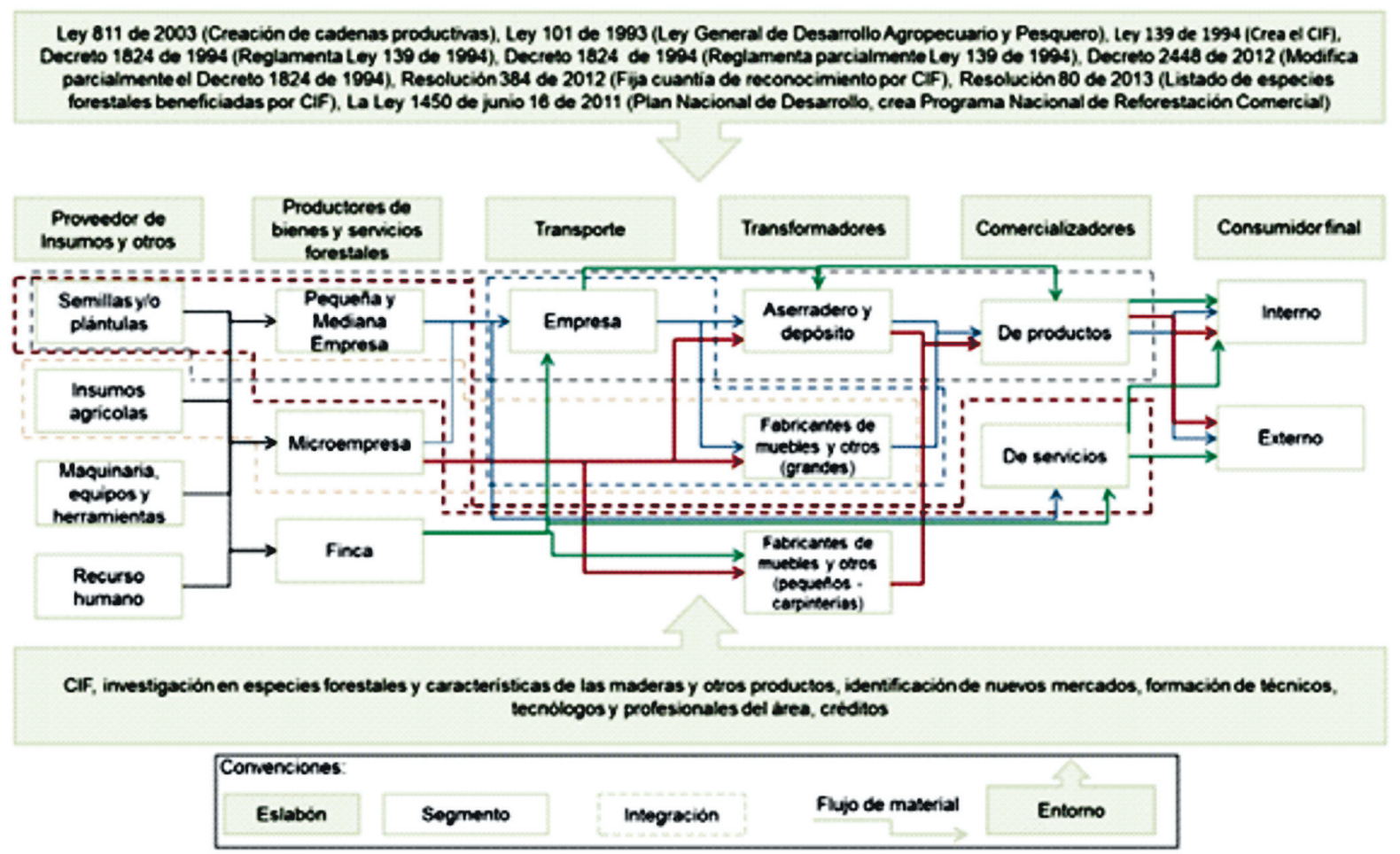

Figura 5. Representación de la propuesta de cadena productiva forestal del departamento de Arauca Fuente: Padilla, 2014, 143 
Tabla 8. Caracterización de los eslabones

\begin{tabular}{|c|c|}
\hline $\begin{array}{l}\text { Eslabón Proveedor } \\
\text { de Insumos y otros }\end{array}$ & $\begin{array}{l}\text { Se plantearon como segmentos potenciales los proveedores de semillas y/o plántulas, producidas } \\
\text { en viveros que en la actualidad no existen en el Departamento, basados en el uso de procesos } \\
\text { de investigación aplicada que faciliten el desarrollo de materias primas de calidad para los pro- } \\
\text { ductores, según sus preferencias de especies o las características de los suelos disponibles para } \\
\text { el establecimiento de plantaciones. También, los proveedores de insumos agrícolas, que en esta } \\
\text { región del país se constituyen como de gran importancia, dadas no sólo las características de los } \\
\text { suelos, sino también las condiciones climáticas preponderantes, correspondientes a dos períodos } \\
\text { extremos, de lluvias y de sequía. El segmento de maquinaria, equipos y herramientas, conside- } \\
\text { rado importante para la tecnificación de la producción, la minimización de costos y tiempos de } \\
\text { mantenimiento de plantaciones, así como la reducción de riesgos en seguridad industrial de las } \\
\text { empresas dedicadas a la producción. Finalmente, aunque no menos importante, la existencia del } \\
\text { segmento recurso humano, dado que la implementación de la cadena productiva forestal y su } \\
\text { desarrollo involucra necesariamente la generación de puestos de trabajo, de diferentes niveles } \\
\text { académicos y funciones y, en ese sentido, es importante contar con oferentes de recurso humano } \\
\text { de nivel operativo, técnico, tecnológico y profesional, de calidad, para facilitar el desarrollo de pro- } \\
\text { cesos de producción, investigación, transformación y comercialización acordes con las exigencias } \\
\text { de los mercados actuales. }\end{array}$ \\
\hline $\begin{array}{l}\text { Eslabón Productores } \\
\text { de bienes y servicios } \\
\text { forestales: producción } \\
\text { forestal primaria: } \\
\text { maderables y servicios } \\
\text { ecosistémicos. }\end{array}$ & $\begin{array}{l}\text { Para este eslabón, se propuso el desarrollo de la pequeña y la mediana empresa principalmente, } \\
\text { dada la necesidad de mantenimiento permanente de la producción que se destinará a ingresar a } \\
\text { los siguientes eslabones de la cadena productiva, colaborando a mejorar el nivel socioeconómico } \\
\text { en las áreas rurales, donde se encuentran las zonas aptas para el establecimiento de plantaciones } \\
\text { forestales comerciales. }\end{array}$ \\
\hline Eslabón Transporte & $\begin{array}{l}\text { Las alianzas entre el sector productivo y de transporte, facilita el desarrollo de procesos de extrac- } \\
\text { ción programados en el tiempo, acordes con los períodos de lluvia y sequía, de tal manera que } \\
\text { no se obstaculicen las vías secundarias y terciarias, desde los puntos de generación de productos } \\
\text { hasta sus centros de acopio, evitando el incremento de los costos asociados a este servicio (lo } \\
\text { cual beneficia al productor) y evitando daños o pérdidas en los vehículos (lo cual beneficia al } \\
\text { transportador). Dadas las características del territorio, desde el punto de vista de estado de las vías } \\
\text { y conflicto armado, probablemente la mejor opción sea la consolidación de grandes asociaciones } \\
\text { de transportadores. }\end{array}$ \\
\hline $\begin{array}{l}\text { Eslabón } \\
\text { Transformadores }\end{array}$ & $\begin{array}{l}\text { El primero de los segmentos propuestos es el de aserradero y depósito, debido a la importancia } \\
\text { de especialización en el manejo y la gestión de productos de madera, especialmente para las } \\
\text { maderas finas, debido a que las características de acopio y almacenamiento temporal requieren } \\
\text { condiciones adecuadas para evitar la pérdida de la producción. En ese sentido, este segmento } \\
\text { requerirá no sólo personal calificado y no calificado, sino también desarrollos tecnológicos a partir } \\
\text { de estas necesidades. Los siguientes segmentos propuestos corresponden a fabricantes de mue- } \\
\text { bles y otros, tanto grandes empresas como pequeños, de la pequeña y mediana empresa, debido } \\
\text { a la importancia de generar productos terminados de calidad para que puedan ser introducidos } \\
\text { a otros mercados potenciales, facilitando la selección de líneas de producción, acordes con las } \\
\text { capacidades técnicas, operativas y de recursos disponibles. En este eslabón se considera impor- } \\
\text { tante incorporar elementos de diseño industrial a los productos con el fin de proporcionarles valor } \\
\text { agregado, lo que puede ser reflejado en el costo para el consumidor final, en diferentes líneas de } \\
\text { producción. }\end{array}$ \\
\hline $\begin{array}{l}\text { Eslabón } \\
\text { Comercializadores }\end{array}$ & $\begin{array}{l}\text { En este eslabón se indicó la división en dos segmentos: comercializadores de productos y comer- } \\
\text { cializadores de servicios. Los comercializadores de productos y servicios deberán tener en cuenta } \\
\text { no sólo el mercado interno (local y nacional), sino también potenciales mercados internacionales } \\
\text { donde puedan tener cabida la producción del Departamento. Los dos segmentos tendrían la } \\
\text { obligación de buscar aliados para la colocación de sus productos y servicios en mercados acor- } \\
\text { des con la calidad y cantidad producida, buscando siempre la introducción en nuevos mercados, } \\
\text { mediante el uso de investigación aplicada a este eslabón, así como de estrategias y herramientas } \\
\text { administrativas y de gestión. } \\
\text { En el segmento de comercialización de servicios, sería importante establecer alianzas con el Esta- } \\
\text { do (instituciones públicas del orden nacional) con el fin de maximizar el impacto de los resultados. }\end{array}$ \\
\hline
\end{tabular}




\section{Eslabón Consumidor final}

Los consumidores finales de los productos y/o servicios generados por la cadena productiva forestal del departamento de Arauca, se constituyen en consumidores internos y externos. Los consumidores internos se ven representados por empresas especialmente de obras civiles que requieren no sólo productos de madera (tablones, postes, etc.), sino también servicios asociados a compensaciones por desarrollo de su actividad comercial, las cuales en su mayoría son establecidas por la autoridad ambiental, con influencia en el Departamento, como reforestaciones de determinadas dimensiones (de acuerdo a las dimensiones de la actividad desarrollada), que deben ser conservadas en el tiempo, cuyas áreas podrían hacer parte de proyectos comerciales protectores-productores, en terrenos con esta vocación. Adicionalmente, se tienen consumidores de productos terminados en pueden ser demandados en el mercado local. Los consumidores externos se ven representados por personas y/o empresas de departamentos cercanos, e incluso de las grandes ciudades de Colombia, que podrían eventualmente requerir productos terminados por su valor agregado y/o particularidades logradas a través de la innovación, además de servicios constituidos en servicios asociados a compensaciones diferentes a reforestaciones, tales como bonos de emisión. El desarrollo de la cadena productiva forestal, a largo plazo, requiere de la integración entre segmentos de diferentes eslabones, consolidando acciones sinérgicas que confluyan en el logro de los objetivos de los segmentos y de la cadena misma.

Fuente: Padilla, 2014

También se hace relevante el fortalecimiento del eslabón de Productores de bienes y servicios forestales, dado su papel de actividad principal de base, sobre la cual se pueden sustentar todos los demás eslabones de la cadena. Ello requerirá de desarrollo de talento humano, así como de nuevos procesos de capacitación y transferencia hacia los actores. Adicionalmente, es relevante considerar las estrategias de nuevos productos, de atención a nuevos mercados o de estrategias de diversificación, en donde los servicios ambientales, la captura de carbono y otras novedades de modalidades con mercados dan la posibilidad de apertura a nuevas ofertas. Decisiones acertadas sobre estos aspectos pueden reducir dependencias a materias primas, hacer más rentables las operaciones, pero especialmente generar consecuencias positivas sobre los bosques naturales y su sostenibilidad en el departamento de Arauca.

\section{Referencias}

Alcaldía de Arauca, 2011. SISTEMA DE GESTIÓN AMBIENTAL PARA EL MUNICIPIO DE ARAUCA. Disponible en: http:// cdim.esap.edu.co/BancoMedios/Documentos\%20PDF/araucaaraucasgam2011.pdf

Arcade J, Godet M, Meunier F, Roubelat F, Mendieta M. 2004. Análisis estructural con el método MICMAC, y estrategia de los actores con el método MACTOR. Buenos Aires: BCNA.

Botero E, Padilla A. Análisis de la realidad competitiva de la cadena forestal en el departamento de Arauca. Contexto. 2015;4:4249.

Casas EC. El desarrollo económico local, el enfoque de desarrollo humano y la economía social y solidaria al servicio de la persona. Revista Perspectiva. 2018;19(2).
Castellanos O, Rojas J, Villarraga L, Ustate E. Conceptualización y papel de la cadena productiva en un entorno de competitividad. Innovar. 2011;18:87-98.

Castellanos O, Torres L, Domínguez K. (2009-b). Manual metodológico para la definición de agendas de investigación y desarrollo tecnológico en cadenas productivas agroindustriales. Ministerio de Agricultura y Desarrollo Rural de Colombia, Bogotá D.C, Colombia: Giro Editores Ltda. ISBN 978-958-8536-04-0.

CID, Centro de Investigaciones para el Desarrollo CID - Universidad Nacional de Colombia. 2005. Documento diagnóstico departamental - Plan estratégico de productividad y competitividad del departamento de Arauca. Bogotá.

Corpoica. 2016. Plan Estratégico de Ciencia, Tecnología e Innovación del Sector Agropecuario Colombiano (2017-2027). Disponible en: http://www.colombiacompetitiva.gov.co/sncei/ Documents/pectia-terminado.pdf

Corporinoquia. 2013. PGAR, Plan de gestión ambiental- regional 2013-2025 https://www.corporinoquia.gov.co/files/pgar/doc_ final_\%20PGAR_2013_2025.pdf

Corporinoquia \& Carbono y Bosques. 2008. Plan general de ordenamiento forestal. Contrato No. 100.14.08.039 de 2008.

DANE. 2014. 3er CENSO NACIONAL AGROPECUARIO, LA MAYOR OPERACIÓN ESTADÍSTICA DEL CAMPO COLOMBIANO EN LOS ÚLTIMOS 45 AÑOS. Disponible en: https://www. dane.gov.co/files/images/foros/foro-de-entrega-de-resultadosy-cierre-3-censo-nacional-agropecuario/CNATomo2-Resultados.pdf

Departamento Nacional de Planeación. 2001. Conpes 3125: Estrategia para la consolidación del plan nacional de desarrollo forestal. Bogotá D.C.

Departamento Nacional de Planeación. 2004. Cadenas productivas. Estructura, comercio internacional y protección. República de Colombia, Bogotá. 
Tabla 9. Niveles de integración

\begin{tabular}{|c|c|}
\hline Flujo de material & $\begin{array}{l}\text { Se propuso la relación generada por los pequeños y medianos productores con las empresas de } \\
\text { transporte a las que contrata para llevar su producción hasta los centros de transformación, cons- } \\
\text { tituidos tanto en aserraderos y depósitos como en fabricantes de muebles (grandes) y, desde alli, } \\
\text { después de su proceso de transformación en productos de madera y otros, los comercializadores } \\
\text { tienen acceso a los mismos hasta el momento de la entrega a los consumidores internos o exter- } \\
\text { nos. Además, los productores de la pequeña y mediana empresa se relacionan con los comerciali- } \\
\text { zadores de servicios, directamente, y éstos con los consumidores internos y externos (color azul). } \\
\text { Los aserraderos y depósitos, se estableció una relación directa entre las microempresas de produc- } \\
\text { tores y los fabricantes de muebles y otros productos, tanto grandes como pequeños, productos } \\
\text { que son comercializados y llevados hasta los consumidores internos y/o externos (color rojo). } \\
\text { Las fincas se relacionaron con las empresas de transporte para trasladar los productos desde sus } \\
\text { terrenos hasta los aserraderos y/o depósitos, o hacia los centros de transformación de los fabri- } \\
\text { cantes de muebles, grandes y pequeños, además, las fincas se relacionan directamente con los } \\
\text { comercializadores de servicios y servicios ambientales, los cuales se relacionan también con los } \\
\text { clientes, internos y externos (color verde). }\end{array}$ \\
\hline Niveles de integración & $\begin{array}{l}\text { a: 1) Los proveedores de semillas y/o plántulas con los productores pequeños y medianos, y éstos } \\
\text { con los transportadores y transformadores del segmento de aserraderos y depósito y, finalmente, } \\
\text { con los comercializadores de productos. Esta integración facilitará el uso de semillas y/o plántulas } \\
\text { adecuadas a los requerimientos de los productores de maderas y otros productos asociados (fibras, } \\
\text { aceites, frutos, etc.) y el desarrollo de procesos investigativos sobre requerimientos reales de los } \\
\text { productores; el aseguramiento del transporte desde los puntos de producción hasta los aserrade- } \\
\text { ros y/o depósitos, desde donde es posible comercializarlos directamente hacia los consumidores fi- } \\
\text { nales o transferir hacia los otros dos segmentos de transformadores (color gris). 2) Los proveedores } \\
\text { de insumos agrícolas con los microempresarios dedicados a la producción forestal y, éstos a su vez, } \\
\text { con los fabricantes de muebles y otros productos terminados de las grandes empresas, las cuales } \\
\text { aseguran el acceso a las materias primas requeridas para asegurar el desarrollo de su actividad y, } \\
\text { además, el bienestar de su empresa y la oferta de permanente de puestos de trabajo calificado y no } \\
\text { calificado (color crema). 3) Las empresas de transporte con los grandes fabricantes de productos } \\
\text { de madera y otros, también asegurando el acceso a materias primas para su proceso de transforma- } \\
\text { ción (color azul). 4) Los proveedores de semillas y/o plántulas con los productores de pequeña y } \\
\text { mediana empresa y, éstos a su vez, con los comercializadores de servicios asociados a las produc- } \\
\text { ción forestal; de esta maneras, se asegura la calidad de las semillas de las especies requeridas para } \\
\text { acceder a mercados y/o incentivos forestales para la producción (en el caso de los productores) } \\
\text { y para la comercialización de servicios (reforestación) y servicios ambientales (bonos de emisión } \\
\text { y turismo, por ejemplo) de acuerdo a requerimientos técnicos y de mercado (color rojo -oscuro). }\end{array}$ \\
\hline $\begin{array}{l}\text { Ambiente } \\
\text { organizacional }\end{array}$ & $\begin{array}{l}\text { Se encuentra el Estado, puede invertir recursos para el desarrollo de la cadena productiva. También } \\
\text { se encuentran los bancos, los cuales, a través de sistemas de créditos especialmente diseñados } \\
\text { para la cadena productiva forestal, facilitan el acceso a recursos para las fases de producción, espe- } \\
\text { cialmente, cuyos tiempos de recuperación de la inversión se consideran lejanos, considerándose } \\
\text { como capitales o inversiones de alto riesgo. De la misma manera, los centros de investigación y } \\
\text { las universidades públicas y privadas pueden desarrollar procesos de investigación aplicada a la } \\
\text { cadena productiva forestal y realizar procesos académicos formales para la capacitación integral } \\
\text { del recurso humano a nivel técnico, tecnológico y profesional en los programas relacionados con } \\
\text { las ciencias forestales (Ingeniería Forestal, Tecnología Forestal) y de otras disciplinas importantes } \\
\text { (administración de empresas, economía, ingeniería industrial, ingeniería ambiental, estadística, eco- } \\
\text { logía, etc.) que se convierten en el soporte del desarrollo próximo de la cadena productiva en el } \\
\text { departamento de Arauca. }\end{array}$ \\
\hline
\end{tabular}


Ambiente institucional

Se encontraron relacionadas las diferentes normas y leyes establecidas por el Gobierno Nacional y sus entidades conexas, para cadenas productivas, incentivos forestales y el plan nacional de reforestación.

La construcción compartida de la misión, visión y objetivos de la cadena productiva forestal, enmarcada en la conciencia colectiva de los actores involucrados y aquellos interesados en su desarrollo, es importante para la creación de fortalezas de grupo relacionadas con la generación de sentido de pertenencia y visualización de escenarios futuros para el desarrollo de esta.

Fuente: (Padilla, 2014).

Departamento Nacional de Planeación. 2011. Plan Nacional de Desarrollo 2010-2014. Prosperidad para Todos. Bogotá.

DNP. 2004. Cadena productiva, Madera y muebles de madera, https://colaboracion.dnp.gov.co/CDT/Desarrollo\%20Empresarial/Maderas.pdf

DNP (2011) Visión de Desarrollo Territorial Departamental CONTENIDO Visión Arauca 2032: Geoestratégica, innovadora y nuestra. Disponible en: https://colaboracion.dnp.gov.co/CDT/ Prensa/Publicaciones/3-VISION\%20ARAUCA.pdf

El Espectador. 2019. "Nos comprometemos a reducir la deforestación en 30\% para el 2022": ministro de Ambiente, Medio Ambiente, 30 Abr 2019 - 12:53 PM. En: https://www.elespectador. com/noticias/medio-ambiente/nos-comprometemos-reducir-ladeforestacion-en-30-para-el-2022-ministro-de-ambiente-articulo-853048?fbclid=IwAR2P7ut7odL5uCBd_hgQR4UYcW8Ekay mqnpny2Iz6IFQClycgYTbjGGaU_A

Espinosa R. 2013. La matriz de análisis DAFO (FODA). Retrieved from Welcome to the new marketing: http://robertoespinosa. es/2013/07/29/la-matriz-de-analisis-dafo-foda/consultado, 18.

FAO. 2005. Mayores beneficios económicos de los bosques: nuevas oportunidades y desafíos. En FAO, Situación de los bosques del mundo (págs. 71-87). Roma, Italia.

FAO. 2011. Estado de los recursos de tierras y aguas del mundo para la alimentación y la agricultura. Roma.

FAO. 2011. Situación de los bosques del mundo. Roma, Italia.

FAO. 2012. El poder de los bosques. Revista internacional de silvicultura e industrias forestales, 63, 88.

FEDEMADERAS. 2011. ACUERDO SECTORIAL DE COMPETITIVIDAD PARA LA CADENA FORESTAL DE LA ORINOQUIA MADERA TABLEROS, MUEBLES Y PRDUCTOS DE MADERA. Villavicencio: Disponible en: http://fedemaderas.org. co/wp-content/uploads/2012/04/3ASC_ORINOQUIA_FINAL_2011-14-05.pdf.

FUNDACIÓN PARA EL DESARROLLO AGRÍCOLA, SOCIAL Y TECNOLÓGICO - FUNDASET. 2006. Marco General y Conceptual del Sector Forestal en la Amazorinoquia. Arauca, Arauca.

Fundaset. 2008. PROPUESTA PARA CONTINUAR CON EL APOYO AL SECTOR FORESTAL DEL DEPARTAMENTO DE ARAUCA. APRODEL CONTRATO NO. 01 DE 2.008 PROYECTO: APOYO AL SECTOR FORESTAL DEL DEPARTAMENTO DE ARAUCA. Disponible en: http://www.tame-arauca.gov.co/Transparen-
cia/PlaneacionGestionyControl/Apoyo\%20al\%20sector\%20 forestal\%20del\%20Departamento\%20de\%20Arauca.pdf

Gobernación de Arauca - Comisión Regional de Competitividad. 2011. Plan Regional de Competitividad del departamento de Arauca. Arauca.

Gobernación de Arauca. 2019. Plan Regional de Competitividad del departamento de Arauca. Disponible en: http://www.competitivas.gov.co/sites/default/files/documentos/arauca.pdf

Gobernación de Arauca. 2002. Diagnóstico de competitividad de la cadena forestal en el departamento de Arauca. Secretaría de Agricultura y Medio Ambiente Departamental - Asociación de profesionales de Arauca, Arauca.

Gobernación de Arauca. 2012. Plan de Desarrollo Departamental de Arauca 2012-2015. Es Hora de Resultados. Arauca, Arauca.

Godet M. 1993. De la anticipación a la acción. Manual de Prospectiva y Estrategia. (Traducido al español). Marcombo. Barcelona.

Godet M.1996. De la anticipación a la acción. Santafé de Bogotá: Alfomega S.A.

Godet M. 2000. La caja de herramientas de la prospectiva estratégica. Paris: Gerpa.

Hernández-Sampieri RC. 2010. Metodología de la investigación. México: Editorial Mc Graw Hill.

Hernández DR, Junco COD, Hernández DR. Metodología para auditar los servicios ecosistémicos forestales en las empresas agroforestales, Pinar del Río, Cuba. Rev Cient Agroeco. 2018;6(2):6-13. https://colaboracion.dnp.gov.co/CDT/ Prensa/Publicaciones/3-VISION\%20ARAUCA.pdf

IDEAM. 2019. Décimo séptimo Boletín de Detecciones Tempranas de Deforestación Cuarto trimestre de 2018 (octubrediciembre). Disponible en: http://www.ideam.gov.co/documents $/ 24277 / 84382637 /$ Detecciones+Tempranas+de+Defor estaci\%C3\%B3n/96e81976-195e-4d0f-8aaf-24c05c7312f8

IICA. 2010. Desarrollo de los agronegocios y la agroindustria rural en América Latina y el Caribe. San José, Costa Rica: IICA.

Merle C. 2018. Estudios de Economía forestal en el marco de la Misión de Crecimiento Verde en Colombia. https://www.dnp. gov.co/Crecimiento-Verde/Documents/ejes-tematicos/forestal/Productos\%20finales/Resumen\%20V2018-09-30.pdf

Min ambiente. 2019. Importancia de los bosques, Colombia tercer país de la región en cobertura boscosa, Disponible en: 
http://www.minambiente.gov.co/index.php/normativa/2noticias/1210-el-uso-sostenible-de-los-bosques-prioridad-deminambiente-513

Ministerio de Agricultura y Desarrollo Rural - Universidad Nacional de Colombia, BioGestión. 2011. Sembrando innovación para la competitividad del sector agropecuario colombiano. Bogotá, Colombia: Giro Editores Ltda.

Ministerio de Agricultura y Desarrollo Rural. 2005. La cadena forestal y madera en Colombia. Bogotá.

Ministerio de Agricultura y Desarrollo Rural. 2007. Cadena productiva forestal - Tableros aglomerados y contrachapados - Muebles y productos de madera. Bogotá, Colombia: Giro Editores Ltda.

Ministerio de Agricultura y Desarrollo Rural. 2008. Cadenas productivas agropecuarias, pesqueras y forestales. Bogotá.

Montoya-Restrepo L. 2010. Gestión de sistemas de integración empresarial. Bogotá D.C.

Montoya-Restrepo L, Montoya-Restrepo I. 2011. Modelos de integración empresarial. Editorial Académica Española.

Navarro KS. Análisis de la Cadena de Abastecimiento del Sector Madera y Muebles de la ciudad de Barranquilla. Scientia et Technica. 2011;3(49):229-238.

ONU. 1992. Agenda 21. Río de Janeiro.

Padilla A, Montoya I, Montoya A. Construcción de escenarios para la cadena forestal en Arauca. ESAP. Revista Administración y Desarrollo. 2015;44(60):69-82.

Padilla A, Montoya A, Montoya I. Construcción de escenarios para la cadena forestal en Arauca. Administración \& DesarroIlo. 2014;(60):68-81.

Padilla A, Montoya A, Montoya I. Análisis Pesta para la consolidación de la cadena productiva forestal en el departamento de Arauca. Punto de Vista. 2017;7(11):155-171
Padilla-Puerta AC. 2014. Propuesta de formulación de la cadena productiva forestal del departamento de Arauca (Doctoral disertación, Universidad Nacional de Colombia-Sede Manizales).

Parra JI. Planeación y la dirección estratégica: futuro de la empresa Colombiana. Revista Universidad EAFIT. 2012;33(105):53-74.

Peña Y, Alemán PAN, Rodríguez FD. Cadenas de valor: un enfoque para las agro cadenas. Equidad \& Desarrollo. 2008;9:77-85.

Presidencia de la República de Colombia. (18 de Diciembre de 1974). Decreto-Ley 2811 de 1974. 71. Bogotá D.E., Colombia.

Presidencia de la República de Colombia. 2013. Contrato Plan de la Nación con el Departamento de Arauca 2013-2020. Arauca.

Rodríguez DMG, Vargas JEB. Modelación dinámica de bienes y servicios ecosistémicos en la reserva forestal productora Thomas van der Hammen. Colombia Forestal. 2018;21(2):188-204.

Upra. 2016. CADENA PRODUCTIVA FORESTAL RELACIONADA CON PLANTACIONES FORESTALES COMERCIALES PARA LA OBTENCIÓN DE MADERA LINEAMIENTOS DE POLÍTICA PARA EL DESARROLLO DEL SECTOR FORESTAL COLOMBIANO. Unidad de Planificación Rural Agropecuaria, UPRA. Disponible en: https://www.upra.gov.co/ documents/10184/11168/Doc_Lineamiento.pdf/65c4d55ba886-457f-b75e-d7f2df5a194b

Uribe-Galvis CP, Fonseca-Rodríguez SL, Bernal-Ramos GE, Contreras-Pedraza CA, Castellanos-Domínguez OF. 2011. Sembrando innovación para la competitividad del sector agropecuario colombiano. Disponible en: http://www.bdigital.unal. edu.co/3567/1/Diagramacion_Libro_MADR_V2.pdf

WWF. 2019. Bosques, riqueza para Colombia. Disponible en: http:// www.wwf.org.co/que_hacemos/bosques/

Zapata JG, Rueda A. 2015. Del Arauca petrolero al Arauca productivo. Disponible en: https://www.repository.fedesarrollo.org. co/bitstream/handle/11445/3019/Repor_Diciembre_2015_ Zapata_y_Rueda.pdf?sequence $=2 \&$ isAllowed $=y$ 